\title{
An automated system for continuous measurements of trace gas fluxes through snow: an evaluation of the gas diffusion method at a subalpine forest site, Niwot Ridge, Colorado
}

\author{
Brian Seok • Detlev Helmig • \\ Mark W. Williams · Daniel Liptzin • \\ Kurt Chowanski $\cdot$ Jacques Hueber
}

Received: 18 September 2008/ Accepted: 24 February 2009/Published online: 6 May 2009

(C) The Author(s) 2009. This article is published with open access at Springerlink.com

\begin{abstract}
An experimental system for sampling trace gas fluxes through seasonal snowpack was deployed at a subalpine site near treeline at Niwot Ridge, Colorado. The sampling manifold was in place throughout the entire snow-covered season for
\end{abstract}

Electronic supplementary material The online version of this article (doi:10.1007/s10533-009-9302-3) contains supplementary material, which is available to authorized users.

B. Seok · D. Helmig · M. W. Williams .

D. Liptzin · K. Chowanski · J. Hueber

Institute of Arctic and Alpine Research (INSTAAR), University of Colorado at Boulder, Boulder,

CO 80309-0450, USA

B. Seok $(\bowtie)$

Department of Atmospheric and Oceanic Sciences, University of Colorado at Boulder, Boulder, CO 80309-0311, USA

e-mail: seok@colorado.edu

M. W. Williams

Department of Geography, University of Colorado at Boulder, Boulder, CO 80309-0260, USA

D. Liptzin

Department of Ecology and Evolutionary Biology, University of Colorado at Boulder, Boulder,

CO 80309-0334, USA

Present Address:

D. Liptzin

Department of Environmental Science, Policy, and Management, University of California at Berkeley, Berkeley, CA 94720-3114, USA continuous air sampling with minimal disturbance to the snowpack. A series of gases (carbon dioxide, water vapor, nitrous oxide, nitric oxide, ozone, volatile organic compounds) was determined in interstitial air withdrawn at eight heights in and above the snowpack at $\sim$ hourly intervals. In this paper, carbon dioxide data from 2007 were used for evaluation of this technique. Ancillary data recorded inlcuded snow physical properties, i.e., temperature, pressure, and density. Various vertical concentration gradients were determined from the multiple height measurements, which allowed calculation of vertical gas fluxes through the snowpack using Fick's 1st law of diffusion. Comparison of flux results obtained from different height inlet combinations show that under most conditions fluxes derived from individual gradient intervals agree with the overall median of all data within a factor of 1.5 . Winds were found to significantly influence gas concentration and gradients in the snowpack. Under the highest observed wind conditions, concentration gradients and calculated fluxes dropped to as low as $13 \%$ of non-wind conditions. Measured differential pressure amplitude exhibited a linear relationship with wind speed. This suggests that wind speed is a sound proxy for assessing advection transport in the snow. Neglecting the wind-pumping effect resulted in considerable underestimation of gas fluxes. An analysis of dependency of fluxes on wind speeds during a 3-week period in mid-winter determined that over this period actual gas fluxes were most likely $57 \%$ higher than 
fluxes calculated by the diffusion method, which omits the wind pumping dependency.

Keywords Diffusion model $\cdot \mathrm{CO}_{2}$ flux .

Gradient method $\cdot$ Snowpack $\cdot$ Wind-pumping

\section{Introduction}

Recent research in snow-covered temperate, alpine, and arctic environments shows that subniveal (under the snow) soil respiration can result in substantial fluxes of carbon dioxide $\left(\mathrm{CO}_{2}\right)$ through the snowpack (Sommerfeld et al. 1993; Brooks et al. 1996; Zimov et al. 1996; Oechel et al. 1997; Mariko et al. 2000; McDowell et al. 2000; Welker et al. 2000; Roehm and Roulet 2003; Monson et al. 2005, 2006). The wintertime $\mathrm{CO}_{2}$ flux through the snow can contribute in excess of $20 \%$ to the annual carbon budget (Winston et al. 1997). To date, studies of trace gas flux through snow have focused primarily on $\mathrm{CO}_{2}$. These findings suggest that microbial processes in underlying soil similarly may drive the flux of other gases such as nitric oxide (NO), nitrous oxide $\left(\mathrm{N}_{2} \mathrm{O}\right)$, and methane $\left(\mathrm{CH}_{4}\right)$. Therefore, these processes warrant consideration in the annual ecosystem carbon $(\mathrm{C})$ and nitrogen $(\mathrm{N})$ budgets of seasonally snow-covered ecosystems (Sommerfeld et al. 1993; Brooks et al. 1996; VanBochove et al. 1996; Mast et al. 1998; Yashiro et al. 2006).

The ecological controls on the trace gas fluxes through the seasonal snowpack are still poorly known, in part because of the difficulty in measuring these fluxes and their dependencies during the winter season. The trace gases $\mathrm{CO}_{2}, \mathrm{CH}_{4}$, and $\mathrm{N}_{2} \mathrm{O}$ are greenhouse gases that play important roles in climate forcing. NO is a precursor of tropospheric ozone $\left(\mathrm{O}_{3}\right)$, which is also a greenhouse gas, formed by photochemical reactions. Several studies have pointed out the high sensitivity of respiration, denitrification, and other processes, which produce these gases, to soil temperature under the seasonal snowpack. In turn, the soil temperature tends to increase with increasing snow depth because the insulating quality of snow cover increases with depth (Brooks and Williams 1999). Consequently, the depth and duration of the seasonal snowpack have been shown to have notable impacts on trace gas exchanges and ecosystem C and N budgets (Williams et al. 1998; Monson et al. 2006). For these reasons, there is a need to better quantify these processes, their behavior, and dependency on conditions such as snowpack properties, snow chemical composition, and soil biogeochemistry, in order to develop conceptual models for the description of these trace gas fluxes under current and future climate conditions.

We have improved experimental protocols for the measurement of fluxes of trace gases through a seasonal snowpack over five winter seasons (20042008) at a high elevation subalpine site in the Colorado Rocky Mountains. Trace gases studied included $\mathrm{CO}_{2}$, nitrogen oxides $\left(\mathrm{NO}_{x}=\mathrm{NO}+\mathrm{NO}_{2}\right)$, $\mathrm{N}_{2} \mathrm{O}, \mathrm{O}_{3}$, and volatile organic compounds (VOC). The high resolution, multiple season data obtained were used to test the gas diffusion model (DM) method for deriving quantitative $\mathrm{C}$ and $\mathrm{N}$ winter balances. The DM approach has been the most common method for evaluating trace gas flux through snow (McDowell et al. 2000), as it has a number of advantages over other flux techniques such as chamber methods and eddy covariance measurements. In particular, the concentrations and gradients of trace gases in the seasonal snowpack are often substantially higher than ambient levels. This allows for more robust measurements and experiments appropriate for complex mountainous terrain and wintertime conditions. Furthermore, these snowpack gradient measurements can be conducted without meeting the stringent requirements for homogenous and flat terrain essential for eddy covariance measurements.

The DM relies on the assumption that gas transfer inside the snowpack is determined by molecular diffusion. However, there are other factors such as pressure-related phenomena that influence gas exchange from the soil through any permeable medium (in particular, snow) to the atmosphere (Massman 2006). A number of studies (Massman et al. 1997; Jones et al. 1999; Hubbard et al. 2005; Takagi et al. 2005; Suzuki et al. 2006) pointed out the large potential error that may occur when the DM approach is applied to trace gas flux through the snowpack because of the effects of advection or wind-pumping. However, quantitative descriptions and corrections of this effect on the flux calculation remain highly uncertain.

In this paper, we present the experimental approach that we have developed over the last 5 years for all winter measurements of trace gas fluxes through a seasonal snowpack. Here, we focus 
on the flux of $\mathrm{CO}_{2}$ during 2007, but believe that this evaluation is applicable to other trace gases and other years. The decision to use $\mathrm{CO}_{2}$ for evaluating our trace gas sampling system was because the $\mathrm{CO}_{2}$ record has been the longest and most complete of all gases studied to date, the relative precision and accuracy of its analytical measurement was highest, thus minimizing errors from the analytical determination, and the $\mathrm{CO}_{2}$ data offered the highest number of comparison with studies reported in the literature. We evaluated potential errors in the estimation of $\mathrm{CO}_{2}$ fluxes through snow including sampling frequency, number of measurement heights within the snowpack, and physical properties of the snowpack such as the density of snow. Errors associated with the DM technique will be discussed with particular emphasis on the influence of wind-pumping. Results and discussion of measured gas fluxes and its ecological significance can be found in papers by Filippa et al. (2009, for $\mathrm{N}_{2} \mathrm{O}$ ), Helmig et al. (2009, for $\mathrm{NO}_{x}$ ), and Liptzin et al. (2009, for $\mathrm{CO}_{2}$ ).

\section{Diffusion model (DM) measurement technique}

The DM method appeared to be most suitable for this study, because it allowed continuous long-term measurements throughout the winter season with relatively simple measurement techniques. This method provided a direct approach to measuring the gas transport through the snowpack, since trace gases were sampled from inside the snow. In past research, gases from the snowpack were typically drawn from two levels, the soil-snow interface and the atmosphere above the snow surface, to obtain a concentration gradient (e.g. Jones et al. 1999; Takagi et al. 2005; Monson et al. 2006; Suzuki et al. 2006). Besides the measurement of trace gases at different heights, the DM method depends on the physical properties of the porous medium. For the snowpack, this involves measurements of snow depth, density, and temperature. A newer technique not evaluated here involves measurements of gas concentration in the snowpack using nondispersive infrared (NDIR) sensors (Takagi et al. 2005).

The DM method is based on Fick's 1st law of diffusion. The underlying theory assumes that the transport of a gas, e.g., $\mathrm{CO}_{2}$, in the snowpack operates primarily in the vertical dimension with fluxes dictated by the concentration differential. Within the horizontal footprint of the $\mathrm{CO}_{2}$ measurement, snow properties are assumed constant in each arbitrary layer of the snowpack, leading to consistent $\mathrm{CO}_{2}$ concentrations at each layer in the snowpack. Thus, $\mathrm{CO}_{2}$ efflux through the snowpack is calculated using the equation

$F_{\mathrm{CO}_{2}}=-D_{\mathrm{CO}_{2}}\left(\frac{\partial C_{\mathrm{CO}_{2}}}{\partial z}\right)$

where $F_{\mathrm{CO}_{2}}$ is the molecular flux of $\mathrm{CO}_{2}$ $\left(\mu \mathrm{mol} \mathrm{m} \mathrm{s}^{-2} \mathrm{~s}^{-1}\right.$ ), $D_{\mathrm{CO}_{2}}$ is the diffusivity of $\mathrm{CO}_{2}$ in the snowpack airspace at the $\partial z$ interval $\left(\mathrm{mol} \mathrm{m}^{2} \mathrm{~s}^{-1}\right)$, and $\partial C_{\mathrm{CO}_{2}} / \partial z$ is the $\mathrm{CO}_{2}$ concentration gradient in the snowpack $\left(\mu \mathrm{mol} \mathrm{m}{ }^{-3}\right)$. Therefore, the flux of gas is directly proportional to the concentration gradient. This indicates that any changes in the concentration gradient term will directly change the flux. The diffusivity $D_{\mathrm{CO}_{2}}$ can be estimated using the relation

$D_{\mathrm{CO}_{2}}=\phi \tau D \frac{P_{0}}{P}\left(\frac{T}{T_{0}}\right)^{\alpha}$,

where $\phi$ is the snowpack porosity, $\tau$ is the tortuosity coefficient, $D$ is the diffusion coefficient of the specific gas under consideration at standard temperature and pressure $\left(T_{0}=273.15 \mathrm{~K}\right.$ and $\left.P_{0}=1,013 \mathrm{hPa}\right)$, i.e., $D=0.1381 \times 10^{-4} \mathrm{~m}^{2} \mathrm{~s}^{-1}$ for $\mathrm{CO}_{2} . P$ is the ambient pressure (hPa), $T$ is the snowpack temperature $(\mathrm{K})$, and the exponent $\alpha=1.81$ is a theoretically set coefficient explained by Massman (1998). Snowpack porosity $\phi$ is calculated by

$\phi=1-\left(\rho_{\text {snow }} / \rho_{\text {ice }}\right)$,

where $\rho_{\text {snow }}$ is the measured density of snow at the $\partial z$ interval $\left(\mathrm{kg} \mathrm{m}^{-3}\right)$, and $\rho_{\text {ice }}$ is the density of ice (917 $\mathrm{kg} \mathrm{m}^{-3}$, Eisenberg and Kauzmann 1969). For the tortuosity constant $\tau$, Duplessis and Masliyah (1991) developed a theoretical relationship where the tortuosity can be derived from the porosity as

$\tau=\frac{1-(1-\phi)^{2 / 3}}{\phi}$.

However, we used

$\tau=\phi^{1 / 3}$,

which is a relationship that was empirically developed from a snowpack in similar regions as our study site (Mast et al. 1998; Hubbard et al. 2005). Some researchers dealt with tortuosity by either ignoring it or by letting it be equal to 1 (e.g. Sommerfeld et al. 
1993), or compensating for its effects by reducing the calculated flux value by $35 \%$ (e.g. Fahnestock et al. 1998).

\section{Materials and methods}

Study site

This study was conducted at the Soddie site on Niwot Ridge in an open meadow surrounded by ribbon forest just below tree line near the Continental Divide in the Colorado Rocky Mountains $\left(40^{\circ} 02^{\prime} 52^{\prime \prime} \mathrm{N}\right.$; $105^{\circ} 34^{\prime} 15^{\prime \prime} \mathrm{W} ; 3,345 \mathrm{~m}$ above sea level). The site is on a $10^{\circ}$ southwest facing slope (Erickson 2004). It has an underground laboratory $3 \times 9 \times 2.4 \mathrm{~m}$ in size, line power, and an array of snow and zero-tension soil lysimeters (Williams et al. 2009). The soil in the open meadow is classified as a mixed Typic Humicryept (Soil Survey Staff 2006) and the forest vegetation is primarily a mixture of spruce (Picea englemannii) and fir (Abies lasiocarpa) [Williams et al. 2009]. The depth of A horizon is $\sim 34 \mathrm{~cm}$; soil composition is $46 \%$ sand, $33 \%$ silt, $21 \%$ clay, and $31 \%$ organic matter in the upper $10 \mathrm{~cm}$. The soil $\mathrm{pH}$ ranges between 4.7 and 5.0 (Seastedt 2001).

\section{Trace gas sampling system}

Snowpack gas flux studies began in the 2003-2004 winter season and have continued with additional gas and physical snowpack measurements. The introduction paper in this issue by Williams et al. (2009) provides the history of the studies. In this manuscript, we report the system configuration from the 20062007 winter season (from here on referred to as winter 2007), because this season has the most extensive measurements to date. The photographs in Fig. 1 and the schematic in Fig. 2 depict the multiinlet snow tower used in winter 2007. The snow tower was constructed of square aluminum alloy $(3.8 \times 3.8 \mathrm{~cm})$ tubing with $60 \mathrm{~cm}$ long cross bars $(1.3 \times 1.3 \mathrm{~cm})$ at heights of $0,10,30,60,90,120$, 150 , and $245 \mathrm{~cm}$ above the ground. The tower was installed in fall 2006, and snow was allowed to accumulate around it. The snowpack surrounding the tower was not disturbed throughout the winter season.

Each of the eight cross bars supported a pair of sampling inlets. The inlets were fitted with
$25 \mathrm{~mm}$ Acrodisc ${ }^{\circledR}$ hydrophobic polytetrafluoroethylene (PTFE) syringe filters (Pall Life Sciences, Ann Arbor, Michigan, USA) to prevent debris from entering the sampling line. Air was drawn at a rate of 1.5-3 $\mathrm{L} \mathrm{min}{ }^{-1}$ from each sampling height depending on the number of chemical measurements conducted. Since the sampling flow was split between the paired inlets, the effective sampling rate per inlet was $0.75-1.5 \mathrm{~L} \mathrm{~min}^{-1}$.

The selection of a pair of inlets for sampling at a particular height on the tower was done through an array of eight solenoid valves. Sampling through each pair of inlets was done sequentially from the $245 \mathrm{~cm}$ height to the $0 \mathrm{~cm}$ height. Each sampling interval was 10 min long, with trace gas contents determined in this gas flow every $10 \mathrm{~s}$. From that record, 1-min averages were calculated for each trace gas, sampling interval, and measurement height. During the transition from one sampling height to the next, concentration readings for both gases adjusted over $\sim 1 \mathrm{~min}$ to the new level at the lower inlet. A complete cycle took $80 \mathrm{~min}$, and there were 18 cycles per day. The manifold used 2-way solenoid valves with PTFE body seals (Cole-Parmer, Vernon Hills, Illinois, USA). All the sampling lines and valves were conditioned over night with a flow of 2-3 $\mathrm{L} \mathrm{min}-1$ of air containing 200-300 ppb ozone prior to installation to minimize the loss of $\mathrm{O}_{3}$ in the manifold during subsequent field sampling. All sampling tubes were directed to the underground laboratory, which housed the analytical instruments. Sampling lines were all perfluoroalkoxy (PFA) Teflon ${ }^{\circledR}$, inner diameter of $3.9 \mathrm{~mm}$ and outer diameter of $6.4 \mathrm{~mm}$ (Parker Hannifin, Cleveland, Ohio, USA), with equal lengths of $18 \mathrm{~m}$. Sections of the sampling lines outside the laboratory were wrapped in pipe insulation with a self-controlling water pipe heater to maintain line temperatures slightly above $0^{\circ} \mathrm{C}$. This was done to prevent water from freezing and clogging the sampling lines.

Monitored gases included $\mathrm{CO}_{2}, \mathrm{H}_{2} \mathrm{O}, \mathrm{NO}_{x}, \mathrm{~N}_{2} \mathrm{O}$, and $\mathrm{O}_{3} \cdot \mathrm{CO}_{2}$ and $\mathrm{H}_{2} \mathrm{O}$ were measured using a LI-7000 IRGA (LI-COR Environmental, Lincoln, Nebraska, USA). $\mathrm{NO}_{x}$ and $\mathrm{O}_{3}$ were measured using a model 42CTL chemiluminescence $\mathrm{NO}_{x}$ analyzer, and model $49 \mathrm{UV}$ photometric $\mathrm{O}_{3}$ analyzer, respectively (Thermo Environmental Instruments, Franklin, Massachusetts, USA). $\mathrm{N}_{2} \mathrm{O}$ was measured by isothermal gas chromatography with electron capture detection (GC-ECD) 
Fig. 1 Series of photographs showing the snowpack sampling tower (snow tower). The left picture was taken before the onset of snowfall in autumn 2006. The upper-right picture shows the snow tower buried in $\sim 2 \mathrm{~m}$ of snow with the top sampling inlet (at $245 \mathrm{~cm}$ ) above the snowpack on 11 March 2007. The lower-right photo shows the syringe fiber glass filter and the type-E thermocouple mounted to one of the ends of the horizontal cross arms on the snow tower

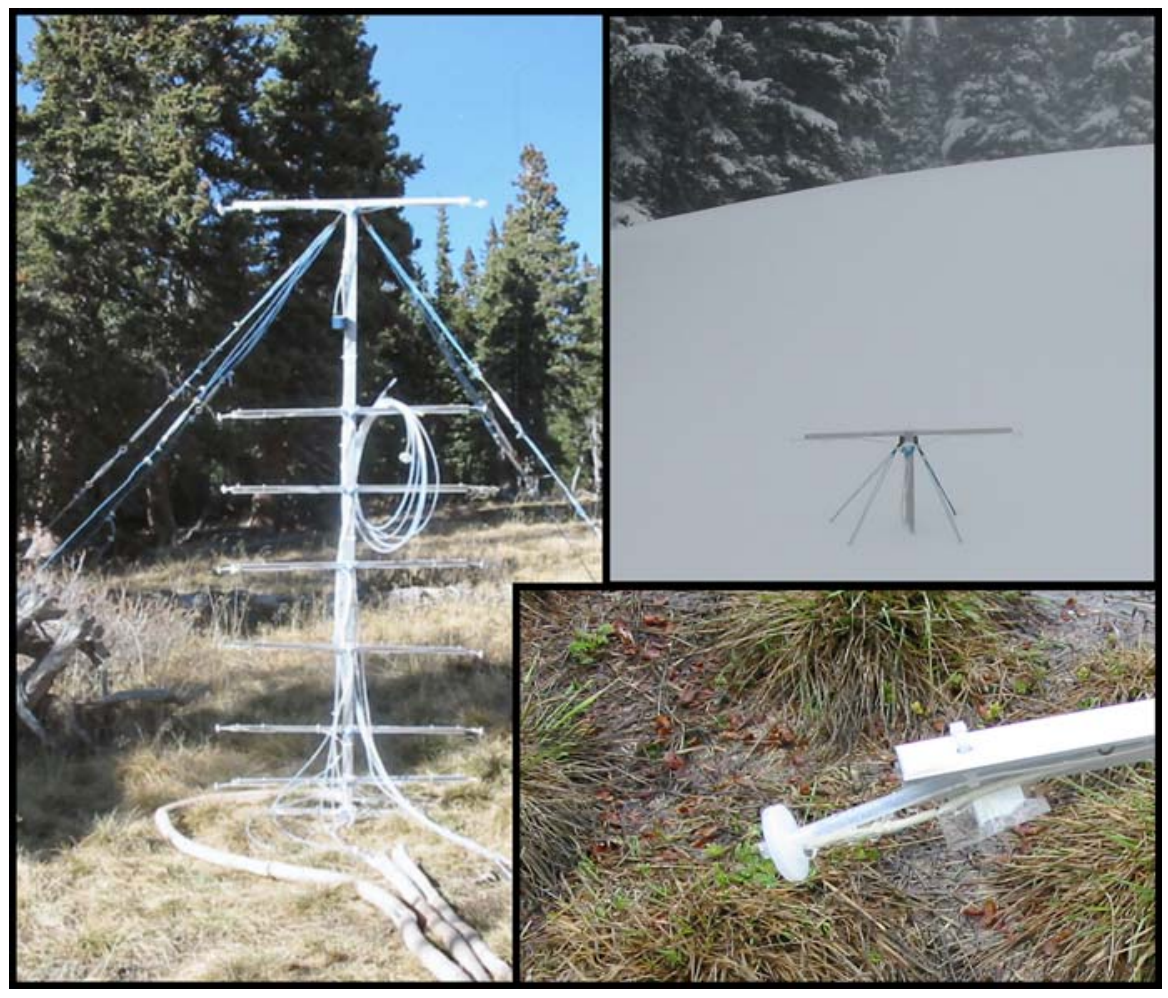

[Shimadzu GC-8AIE, Shimadzu Scientific Instruments, Columbia, Maryland, USA]. On site instrument calibrations for the LI-7000 IRGA, the model 42CTL chemiluminescence $\mathrm{NO}_{x}$ analyzer, and the Shimadzu GC-8AIE were automated. More details on these analytical measurements and calibration procedures are presented elsewhere (Filippa et al. 2009, for the GC-8AIE; Helmig et al. 2009, for the 42CTL; Liptzin et al. 2009, for the LI-7000 IRGA). The sampling manifold, calibration system, and data acquisition were controlled through an array of digital input/ output modules, temperature input components, and LabVIEW software (National Instruments, Austin, Texas, USA). The GC-ECD signals were acquired through a PeakSimple system (SRI Instruments, Torrance, California, USA).

\section{Ancillary data}

Temperatures at each sampling height were measured using type-E thermocouples (Omega Engineering, Inc., Stamford, Connecticut, USA) that were covered by white shrink tubing to reduce radiation artifacts. Wind speed, at $6 \mathrm{~m}$ above the ground on a meteorological (MET) tower $10 \mathrm{~m}$ away, was measured using a 05103-L R.M. Young Wind Monitor (Campbell Scientific, Logan, Utah, USA). Barometric pressure was measured using a CS105 Vaisala PTB101B Barometer (Campbell Scientific, Logan, Utah, USA). Differential pressure between the soilsnow and snow-atmosphere interfaces was collected at the MET tower using a differential pressure sensor (PX277-0.1D5V, Omega Engineering, Inc., Stamford, Connecticut, USA) with $1 \mathrm{~Hz}$ sampling rate and 1-min averages stored. The high pressure inlet was placed at $3 \mathrm{~m}$ above the soil surface and the low pressure inlet was placed on the ground. Given this setup, if pressure at the ground was greater than at the snow surface, then the resulting pressure gradient was measured as a negative signal.

Readings of snow depth were conducted at 1-2 week intervals from calibrated marks on the snow tower. Gaps in the snow depth record were filled by comparing and interpolating the daily snow depth record from the SNOTEL site, $1.5 \mathrm{~km}$ from the Soddie. An analysis of the linear correlation between concurrent snow-depth data from these two sites resulted in a $r^{2}=0.91$. These snow depth data were 


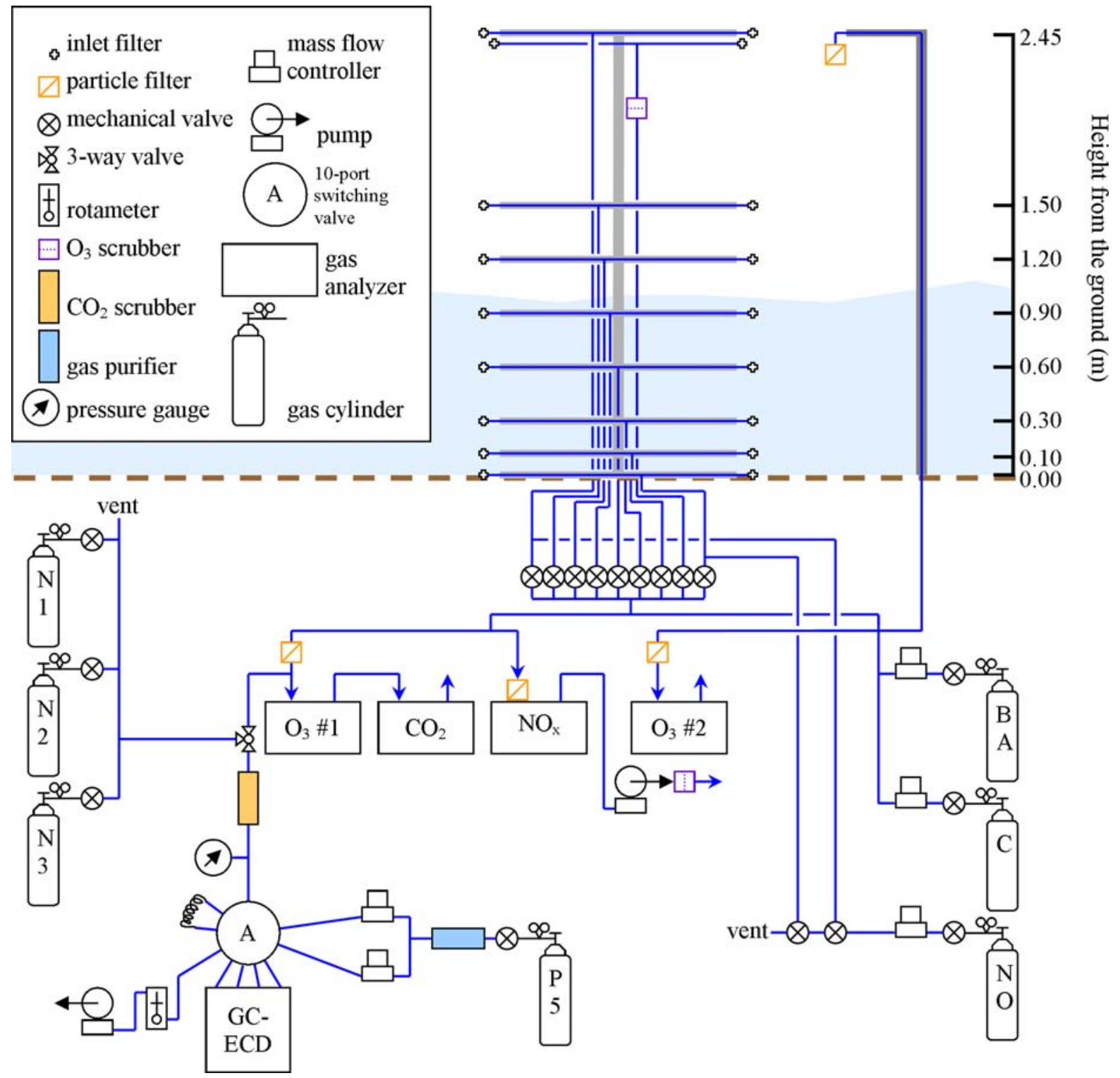

Fig. 2 Schematics of winter 2007 season snowpack sampling tower with plumbing and instrument configuration. The skyblue dotted pattern area is the snowpack. The brown dashed line defines the ground. The instruments are located in an underground lab. Abbreviations of the cylinder labels in the

used for flux calculations including the ambient air measurement data $(245 \mathrm{~cm})$. An effective snowpack diffusion distance to the snow surface was determined by calculating the distance from the respective, fixed height inlet pair to this determined snow surface height. Gas measurements from the $245 \mathrm{~cm}$ height were assumed to be representative for conditions at the snow-atmosphere interface. This simplification diagram reflect the following: $\mathrm{BA}=$ breathing air standard, $\mathrm{C}=1 \% \quad \mathrm{CO}_{2} \quad$ standard, $\quad \mathrm{N} 1=320 \mathrm{ppb} \quad \mathrm{N}_{2} \mathrm{O} \quad$ standard, $\mathrm{N} 2=408 \mathrm{ppb} \mathrm{N}_{2} \mathrm{O}$ standard, $\mathrm{N} 3=485 \mathrm{ppb} \mathrm{N}_{2} \mathrm{O}$ standard, $\mathrm{NO}=100$ ppb NO standard, P5 $=5 \% \mathrm{CH}_{4} / 95 \%$ Ar carrier gas (Color figure online)

neglects the concentration gradients between the snow surface and the $245 \mathrm{~cm}$ height.

Soil moisture was measured using four CS616-L Water Content Reflectometers with $30 \mathrm{~cm}$ long probes installed vertically into the soil in a $1 \mathrm{~m}$ radius from the snow tower (Campbell Scientific, Logan, Utah, USA), following the protocol at the C-1 Ameriflux site on Niwot Ridge (Bowling et al. 2009), 
with the average of the four sensors used for all further data applications.

Snow density was measured in an adjacent open meadow area $\sim 30$ m away from the primary study site with similar vegetation and slope characteristics. Snow pits were dug every 1-2 weeks, upslope first and progressed downhill for each new snow pit. Snow properties including depth, density, grain type, grain size, and stratigraphy were measured using previously published protocols (Williams et al. 1996, 1999).

\section{Results}

Snow physical properties

Continuous snowpack at this site typically develops between the end of October and early November. The seasonal snow cover reached a maximum depth of $2.2 \mathrm{~m}$ in March 2007, and all snow had melted by the first week of June (Fig. 3). The snowpack development in 2007 was similar to our five seasons of measurements, where seasonal maximum snowpack depths of 1.8-2.2 m occurred between day of year (DOY) 65 and 85. While there were occasional minor reductions in snowpack depth throughout the winter, with a more significant one occurring during DOY 80-85 in 2007, the springtime snow melt with significant and continuous snow depth reductions did not commence until DOY 130. The physical changes associated with this transition are also evident in the temperature and density records.

Snowpack temperatures were usually warmer than ambient air temperatures throughout the season (Fig. 3a). The average air temperature during the snow-covered period was $-5.2^{\circ} \mathrm{C}$, with minimum values of $-25^{\circ} \mathrm{C}$ in mid-winter and an increasing trend in late winter and early spring. The diurnal and daily fluctuations of air temperature progressively damped within the first $10-50 \mathrm{~cm}$ below the snow surface. The temperature at the soil-snow interface increased to about $0^{\circ} \mathrm{C}$ when the snowpack reached a depth of $\sim 12 \mathrm{~cm}$ and remained as such until the end of the season (Fig. 3a). At DOY 67, the upper snowpack layers suddenly warmed. The entire snowpack turned isothermal over an 8 day period. However, it took another 55 days from that point until significant snow melt occurred.

Snowpack density generally increased over time (Fig. 3b). The initial density was $\sim 200 \mathrm{~kg} \mathrm{~m}^{-3}$ early
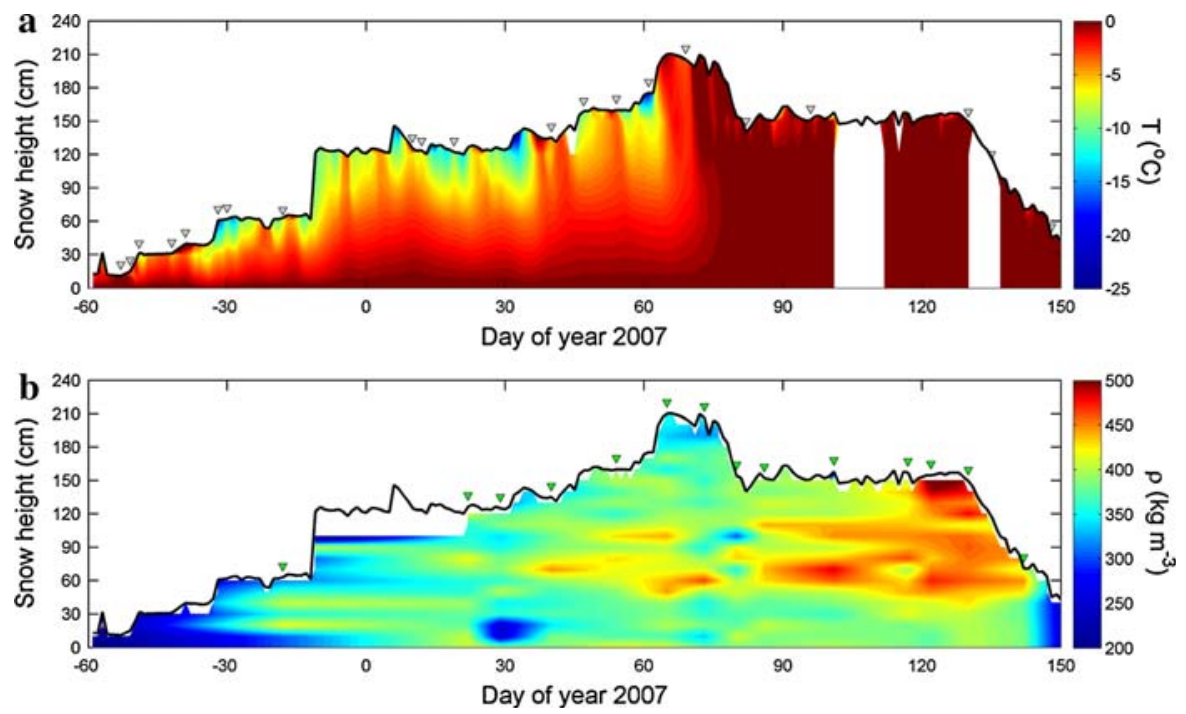

Fig. 3 a A temporal and vertical development of the snowpack temperature. The black solid line is the snow height above the ground $(\mathrm{cm})$. The color bar is the snowpack temperature $\left({ }^{\circ} \mathrm{C}\right)$. The inverted dark grey triangles denote time when actual snow depth measurements were taken. The gaps in the snow depth data were filled through extrapolating daily snow depth measurements from the nearby SNOTEL site (see text for details). b Contour plot of snow density $\left(\mathrm{kg} \mathrm{m}^{-3}\right)$ generated from the biweekly snow pit excavation with $10-\mathrm{cm}$ vertical resolution. The inverted green triangles denote the dates when actual snow density samples were taken. Gaps between sampling periods were filled through linear interpolation (Color figure online) 
in the season; the maximum density measured of $500 \mathrm{~kg} \mathrm{~m}^{-3}$ occurred during the snowmelt period. Density normally increased with depth due to compression caused by the overlying snow. However, at depths below $60 \mathrm{~cm}$, density remained lower and showed little change over time until active snowmelt. This section of the snowpack was composed of kinetic grains (depth hoar), which resists compression.

$\mathrm{CO}_{2}$ and $\mathrm{H}_{2} \mathrm{O}$ vapor concentrations within the snowpack

A typical plot of the snowpack concentrations of $\mathrm{CO}_{2}$ and $\mathrm{H}_{2} \mathrm{O}$ vapor during a sampling cycle is presented in Fig. 4. After $3 \mathrm{~min}$ of the transition between levels, concentrations of $\mathrm{CO}_{2}$ and $\mathrm{H}_{2} \mathrm{O}$ vapor remained relatively constant for the remainder of the measurement interval. Because of the changing signal during the transition from one inlet to the next, the five points around the transition period were omitted for calculating the gas concentration for each measurement time interval (Fig. 4).
$\mathrm{CO}_{2}$ fluxes

The time series of calculated daily mean fluxes from all possible gradient combinations for winter 2007 is shown in Fig. 5. These data show a remarkable variability both between results from different inlet heights and between measurement days. Figure 5 also shows the median value calculated from all available gradient interval fluxes at a given time. Closer inspection of this record revealed that individual gradient data typically fall within a range of $\pm 50 \%$ of the overall median, but it was not uncommon that data from a selected gradient deviated up to $100 \%$ from the median. Results derived from measurements at the $0 \mathrm{~cm}$ inlet frequently deviated from the other inlet data, with gradients between the 0 and $10 \mathrm{~cm}$ inlets often being unusually small and on occasion even negative. This behavior was interpreted as this measurement interval being too close to the ground and within the surface roughness layer at this site, where consistent gradients are not well developed. Figure 5 also shows the median value calculated from
Fig. 4 Example of a time series of $\mathrm{CO}_{2}$ and $\mathrm{H}_{2} \mathrm{O}$ vapor concentration data during one sampling cycle on 11 March 2007 with the $x$-axis scale indicating time from the beginning of the cycle $(2: 40 \mathrm{am})$. The dots are 1-min averages of data collected every $10 \mathrm{~s}$. The white dots in each 10-min sampling interval represent the data that were averaged for determining gas concentration gradients $(\partial C / \partial z)$. The black dots were omitted from the calculation for determining the gas concentration gradient because the values may be compromised during the switching between sampling inlets. The snowpack depth during this sampling cycle was $1.87 \mathrm{~m}$
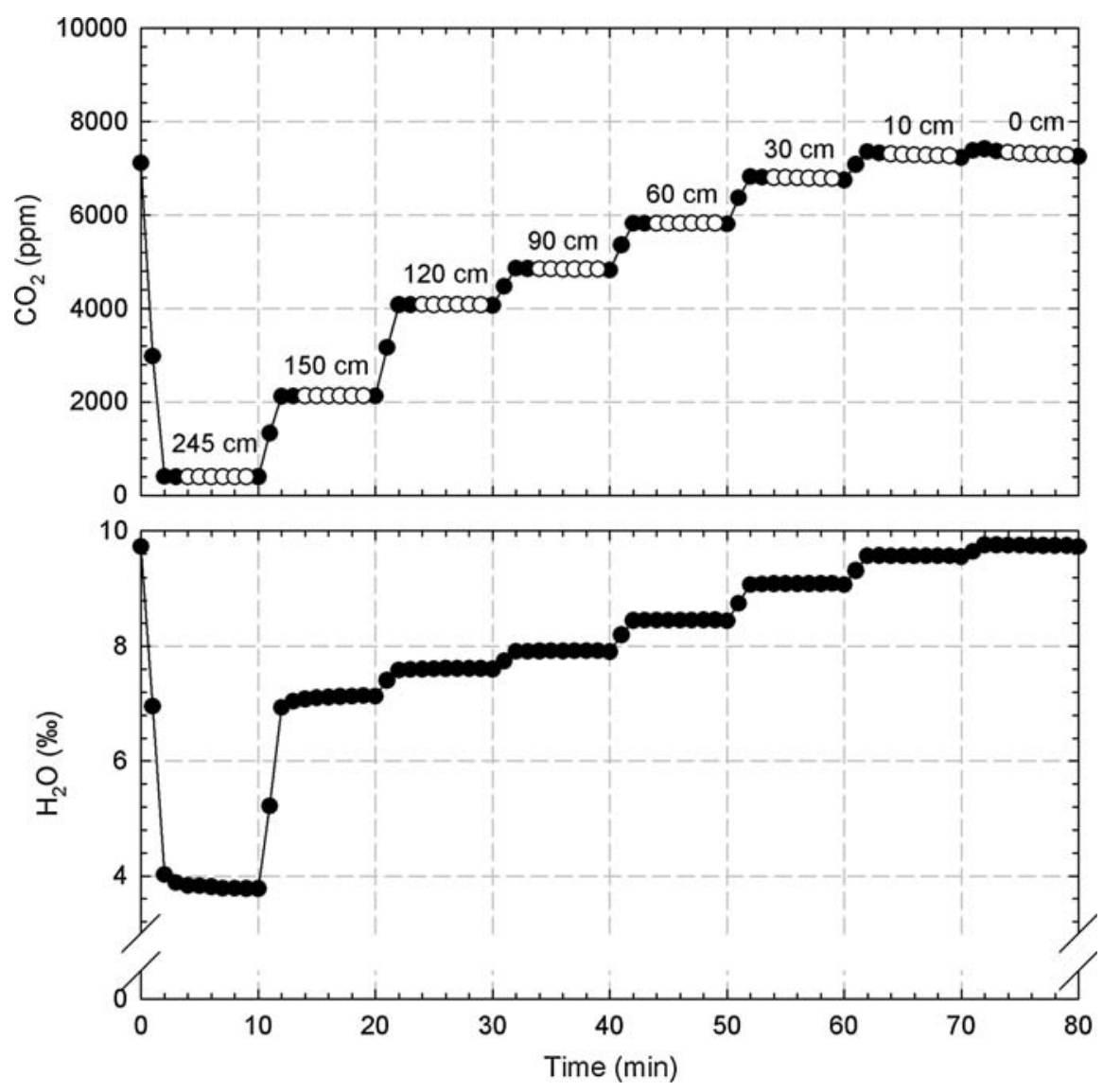
Fig. 5 Daily winter 2007 $\mathrm{CO}_{2}$ flux for all sampling height combination. The thick black line depicts the daily median flux data calculated from the results of all gradient combinations (Color figure online)

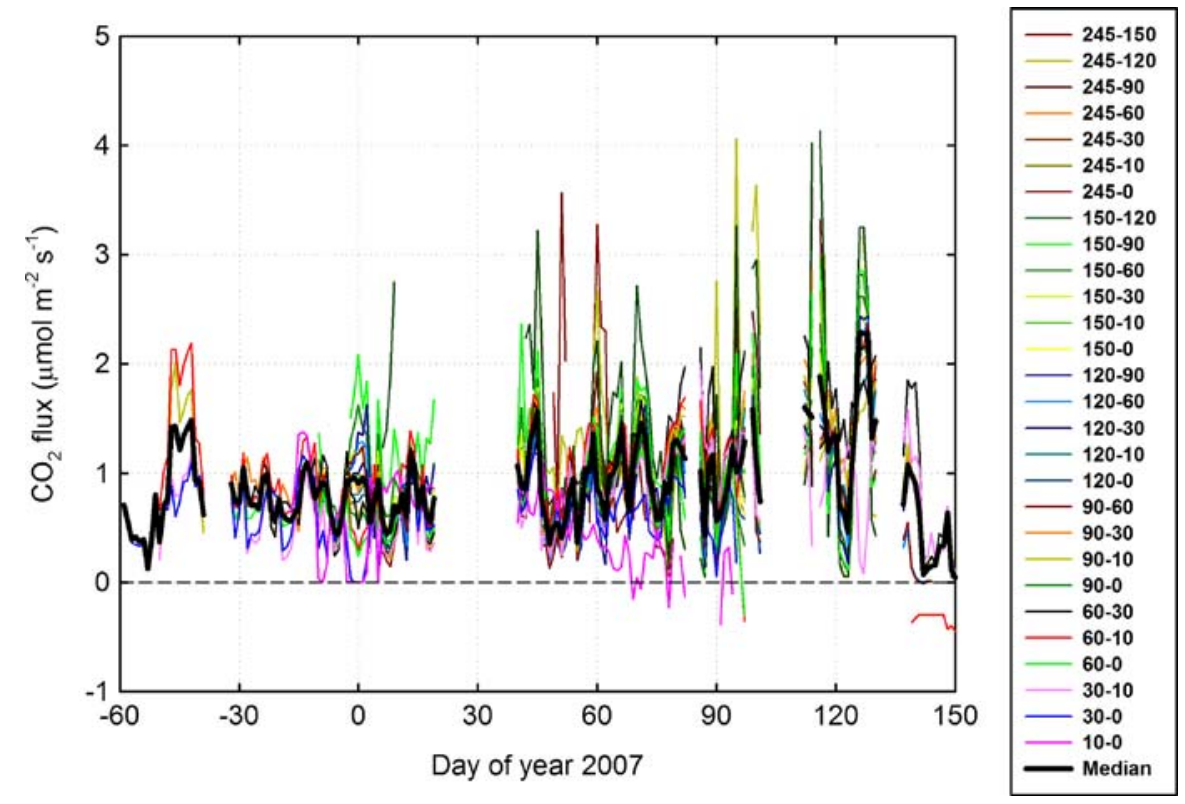

all available gradient interval fluxes at a given time. Our estimate of the diffusive $\mathrm{CO}_{2}$ flux based on the seasonal average of the daily mean ranged from 0.58 to $1.08 \mu \mathrm{mol} \mathrm{m} \mathrm{m}^{-2} \mathrm{~s}^{-1}$ in 2007 , depending on the pairs of inlets used for the gradient calculation (Fig. 5). However, of the 27 gradient combinations, sixteen of them gave results between 0.70 and $0.90 \mu \mathrm{mol}$ $\mathrm{m}^{-2} \mathrm{~s}^{-1}$. The linear correlation of the all-season data from the 27 gradient combinations illustrated thatnot unexpectedly-correlations were highest where gradient intervals overlap due to the autocorrelation in these data. For example, the correlation coefficient for gradients calculated from 90 to $60 \mathrm{~cm}$ and from 120 to $30 \mathrm{~cm}$ was 0.99 . Furthermore, correlations were high for data from adjacent gradients (please see Fig. 4 in Filippa et al. (2009), which graphically displays the corresponding analysis for calculated $\mathrm{N}_{2} \mathrm{O}$ fluxes from the $90-60 \mathrm{~cm}$ vs. the $60-30 \mathrm{~cm}$ gradient data), and became weaker the further the gradients were separated vertically. Also, better agreement was generally seen in data from the middle of the snowpack, whereas results from sampling near the bottom and involving measurements from the ambient inlet often showed weaker correlations. The correlation coefficient $r$ was only 0.29 between gradients calculated from 30 to $10 \mathrm{~cm}$ and from 120 to $90 \mathrm{~cm}$. In essence, the linear correlation results of the fluxes were dictated by the concentration gradient, as shown in Eq. (1). Absolute correlation values $r$ of 1 or close to 1 between different-height gradients implied that the fluxes through the snowpack were constant, which is a key assumption of the DM. This behavior also implies that diffusion was the dominant process in the transport of $\mathrm{CO}_{2}$ though the snowpack. Our multiple-inlet gradient and flux data illustrate that for the center portion of the snowpack, these conditions (i.e., linear concentration gradients and dominant diffusion transport) were reasonably well met and that the diffusion model was an appropriate tool for estimating fluxes. Consequently, most of our subsequent analyzes were done using the data from the $60-30 \mathrm{~cm}$ gradient interval. These data showed relatively high correlation with most non-overlapping inlet pair combination (range in $r$ values of $0.29-0.80$ ). Furthermore, the $60-30 \mathrm{~cm}$ inlet data were the longest and most steady record for the 2005-2006 winter season (here on as winter 2006) and winter 2007 .

\section{Discussion}

Potential sampling effects

Active sampling from interstitial air in the snowpack represents a disturbance to the natural air transport and this can generate artifacts in the measured snowpack data (Albert et al. 2002; Domine et al. 2008). We evaluated the potential artifact caused by our sampling 
technique using an approach similar to the one presented by Bowling et al. (2009). Our sampling system pulled $\sim 20 \mathrm{~L}$ of air from the paired inlets during each sampling interval. The $\sim 10 \mathrm{~L}$ of air withdrawn at each inlet, at a snowpack density of $400 \mathrm{~kg} \mathrm{~m}^{-3}$ (which was the seasonal average), and assuming a sphere volume, would yield an effective radius of $\sim 16 \mathrm{~cm}$ per inlet of the sampling volume. All, but one, sampling ports were $30 \mathrm{~cm}$ apart in the vertical, so there is very little overlap within this radius. (The closer distance between the 0 and $10 \mathrm{~cm}$ height inlet pairs was the only exception to this requirement). Based on gas-phase diffusive transport only (Seinfeld and Pandis 2006, p 551), we estimated that it would take $\sim 44 \mathrm{~min}$ within this volume for air to re-equilibrate to its original condition. This is faster than the 80-min cycle used in our experiment. [With increased (decreased) snow density, the re-equilibrium time would increase (decrease), and the sample will reflect a larger (smaller) volume of snowpack]. Data from our sampling protocol confirmed the validity of these assumptions. As seen in Fig. 4, other than during the transition period, there was comparatively little change in gas concentrations during the 10-min sampling interval. This meant that gas sampled during this time remained relatively representative of the given inlet height. Also, closer inspection of these records revealed that the relative change of signal was largest for the $0 \mathrm{~cm}$ measurement height, which reflects the fact that the available airspace extends only in one direction; therefore, air that replaced the sampled air volume is expected to be drawn from a larger vertical distance. The larger degree of overlapping sampling volumes for the 0 and $10 \mathrm{~cm}$ heights explained to some extend the deviating behavior in observed gradient from these two heights. In summary, our results were in agreement with the findings of Bowling et al. (2009) who re-measured several inlets $25 \mathrm{~min}$ after the initial measurement and found no difference in $\mathrm{CO}_{2}$ concentrations or isotopes of carbon and concluded that the advective influence of their sampling under these conditions was negligible.

Dependence of $\mathrm{CO}_{2}$ flux on environmental conditions

In general, $\mathrm{CO}_{2}$ fluxes gradually increased over the snow-covered season, reaching a maximum around the onset of snowmelt. An interesting question was what drove the daily variations in $\mathrm{CO}_{2}$ (Fig. 5), and if the change in flux was driven by changes in the source term, i.e., day-to-day changes in the emission of $\mathrm{CO}_{2}$ from soil to the snowpack, or to other physical or chemical processes that influenced the flux calculation. For the investigation of this question, we focused on the 30-day time period between DOY -11 and 19 when the snow depth was relatively constant at $\sim 120 \mathrm{~cm}$ (Fig. 6a). Over this time span, the soil volumetric water content remained constant at $\sim 0.20 \mathrm{~m}^{3} \mathrm{~m}^{-3}$ (Fig. 6b), and the temperature near the soil-snow interface was always $\sim 0^{\circ} \mathrm{C}$ (Fig. $6 \mathrm{~d}$ ). In contrast to the relatively constant snow depth, snow temperature, and soil moisture content, data for wind speed ranged over more than an order of magnitude from $<0.2$ to $6 \mathrm{~m} \mathrm{~s}^{-1}$ (Fig. 6c). In turn, there was a tendency that higher wind speeds were associated with lower differential pressures (Fig. 6c). Concentrations of $\mathrm{CO}_{2}$ increased from ambient levels at the snow surface $(\sim 385 \mathrm{ppm})$ to $\sim 4,000 \mathrm{ppm}$ at the bottom of the snowpack (Fig. 6e). Comparison between the $\mathrm{CO}_{2}$ concentration and wind speed time series data suggested that $\mathrm{CO}_{2}$ concentrations in the snowpack generally decreased with increasing wind speed. For example, between DOY -6 and -5 , at the $10 \mathrm{~cm}$ level, $\mathrm{CO}_{2}$ concentrations decreased by almost a factor of 2 from 2,690 to $1,475 \mathrm{ppm}$, as wind speed increased from 1.5 to $5.9 \mathrm{~m} \mathrm{~s}^{-1}$. As a result, calculated $\mathrm{CO}_{2}$ fluxes decreased from 0.67 to $0.16 \mu \mathrm{mol} \mathrm{m}^{-2} \mathrm{~s}^{-1}$ (Fig. 6f).

Uncertainties in flux estimates using the diffusion model

Snow permeability and gas transport are related to snow density (Albert and Hardy 1995; Albert and Shultz 2002; Albert et al. 2004) as permeability is affected by porosity and tortuosity, even though there is no direct relationship between porosity, tortuosity, and permeability (Hardy et al. 1995). In our flux calculation, gas diffusivity, following Eq. (2), was derived indirectly from snow density, as porosity and tortuosity were calculated from the density values [see Eqs. (3) and (5)]. For example, the diffusion rate at a density of $250 \mathrm{~kg} \mathrm{~m}^{-3}$ was $87 \%$ faster than at a density of $500 \mathrm{~kg} \mathrm{~m}^{-3}$, assuming all other variables were unchanged. Thus, errors in the estimate of $\mathrm{CO}_{2}$ flux through snow caused by incorrect measurements of density varied as density changed. Errors in measuring the density of snow have been estimated 
Fig. 6 Dataset from DOY -11 to 19 . a Snow height from the ground. The grey dots are the actual snow depth measurements. The solid line is the interpolated data based on the daily SNOTEL snow depth measurements (see text for details). b Soil moisture data. The line is the average of the four soil moisture sensors surrounding the snow tower in a $1-\mathrm{m}$ radius. c Wind speed (dark blue solid line) and differential pressure (sky-blue solid line). d Temperature data from the snow tower (in and above the snowpack). e $\mathrm{CO}_{2}$ concentration in and above the snowpack measured from the snow tower. The green and red arrows mark the start and end when the instrument range was maxed out at $3000 \mathrm{ppm}$ at one or more sampling heights. f Calculated flux using the 30 and $60 \mathrm{~cm}$ inlet data without consideration of wind correction (Color figure online)
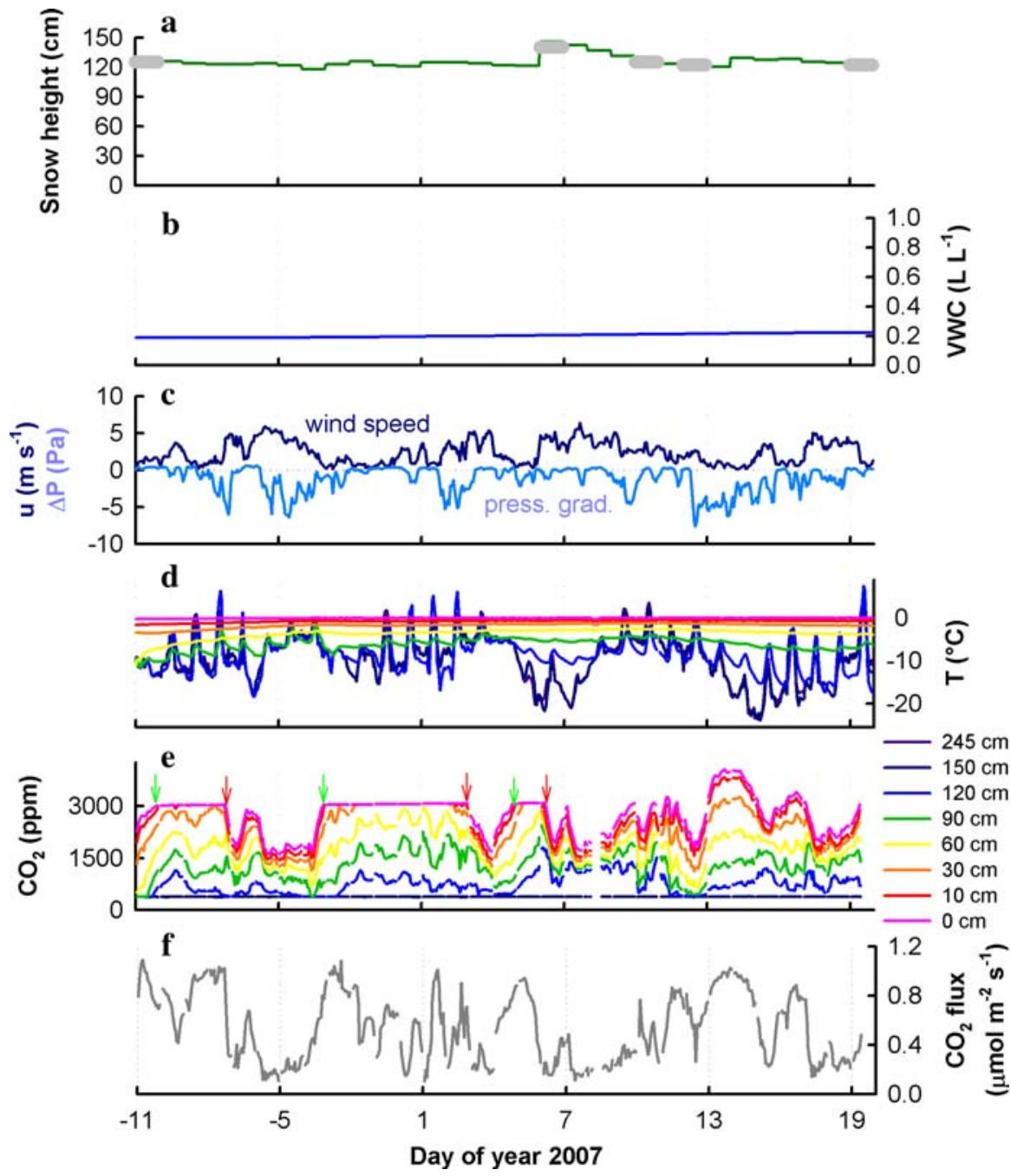

at $10-15 \%$ (Sommerfeld et al. 1996; Hubbard et al. 2005). In our case, the uncertainty in applied density was likely higher, as we applied density data from an adjacent plot, and the biweekly density determinations did not allow for capturing density changes that occurred at higher frequency than this sampling interval. We evaluated how errors in measuring density propagated to errors in estimating the flux of $\mathrm{CO}_{2}$ using errors in the measurement of density of $\pm 10,20$, and $30 \%$. The calculated error increased non-linearly at higher snow densities and with the uncertainty in the determination of snow density. For instance, a $10 \%$ error in the measurement of snow density resulted in an error in the estimated $\mathrm{CO}_{2}$ flux on the order $5 \%$ for a snow density of $300 \mathrm{~kg} \mathrm{~m}^{-3}$ but more than $10 \%$ at a density of $500 \mathrm{~kg} \mathrm{~m}^{-3}$. For the range of snow densities encountered during the experiment at the Soddie sites, we estimated that the error in calculating the flux of $\mathrm{CO}_{2}$ ranged from 2 to 9\% (Supplementary Material, Fig. S1). Another potential complication in the diffusion flux calculation was the presence of crust and ice layers, which may constitute diffusion barriers that were not considered in the Fick's law calculation. Snow pit analyses showed that ice layers were uncommon at the site, as snow surface temperatures at this high elevation generally remain below freezing (which avoids freeze-thaw events that form crust and ice layers) until the onset of the spring melt period. There are several reasons why our sampling technique is rather robust against the influence of inhomogeneous snow density, and ice lenses and crusts. The variation 
of snowpack density was accounted for in the flux calculation. For each sampling interval, the snowpack density corresponding to that sampling interval and snowpack layer was used to calculate the fluxes. This resolves the temporal and spatial variations the snowpack density would have on the flux. Conceptually, our sampling system in the snowpack was similar to a chamber with open sides giving it horizontally infinite spatial scale. Since ice lenses and crusts do not span over an infinitely large area, gases diffusing through the snowpack would continue to travel around the ice lenses and crusts, and gas concentration at each arbitrary horizontal layer in the snowpack would equilibrate and maintain a distinct concentration gradient. The deviation in flux results from different height intervals affirms (Fig. 5) and defines the maximum effect that this error; as already elucidated above, these data show that flux results generally agreed within a factor of 1.5 from different height intervals.

Errors in the measurement of the snowpack height and the height of the tower arms were also a source of uncertainty when calculating the flux of $\mathrm{CO}_{2}$. All gradient distances within the snowpack were determined by the distance between the tower cross arms. Due to the pressure exhibited from the compacting and creeping snow, some of the cross arms were bent by up to $5 \mathrm{~cm}$, which introduces an error of as much as $15 \%$ in the flux calculation. The flux from any inlet to the snow surface depended on the accuracy on the snow depth determination. The associated error would be variable, depending on the time passed from the last visual inspection, and the accuracy of the interpolation from the SNOTEL record. Furthermore, this error relied on the absolute distance of the respective inlet to the snow surface. As this error propagated, its relative value would be larger for inlets closer to the atmosphere than for inlets nearer to the soil surface. We estimated the overall range of the error contributed from uncertainties in the gradient interval to the surface to be on the order of 10 to $100 \%$ in the most extreme cases; the latter for inlets very close to the snow surface. Temperature measurements inside the snowpack are expected to have a minor contribution $(<5 \%)$ to the error estimate, as snowpack air temperatures were measured with a relative high accuracy and showed little variation with time and space (Fig. 3). This error may increase slightly nearer to the surface where temperature changes were more pronounced than deeper in the snow.

We also investigated how sampling frequency may bias the flux calculation. Among previous studies the frequency of measurements varied widely, ranging from as often as half-hourly (e.g., Musselman et al. 2005) to as few as twice per winter (e.g., Hubbard et al. 2005). We used a bootstrap randomization without replacement test to examine the sampling frequency effects (Supplementary Material, Fig. S2). First, we calculated a daytime ( 9 a.m. -5 p.m.) mean to provide a more realistic comparison to manual sampling protocols. For each sampling frequency the appropriate number of daytime values (ranging from 5 to 120 days) was randomly selected and a mean calculated. This process of calculating means was repeated 1,000 times, and the $95 \%$ confidence interval was determined as the 25th and 975th mean (Manly 1997). The $95 \%$ confidence limit for the continuous data was $0.69-0.82 \mu \mathrm{mol} \mathrm{m} \mathrm{m}^{-2} \mathrm{~s}^{-1}$ in 2007. Monthly sampling resulted in an increase in the $95 \%$ confidence interval ranging from 0.5 to $1.1 \mu \mathrm{mol} \mathrm{m} \mathrm{m}^{-2} \mathrm{~s}^{-1}$. The $95 \%$ confidence interval for weekly sampling (30 samples) of $0.62-0.88 \mu \mathrm{mol} \mathrm{m}{ }^{-2} \mathrm{~s}^{-1}$ moved close to the results from our continuous measurements. The results from this bootstrap analysis meant that a weekly sampling frequency (i.e. one gradient per week) would give a mean flux value that was within $\pm 10 \%$ of the results from our continuous measurements of $\mathrm{CO}_{2}$ flux.

Assessment of advection on flux calculations

The observed day-to-day variability in calculated fluxes and differences in results from different gradient intervals fully cannot be accounted for even when combing all of the above considered sampling and measurement errors and uncertainties, consequently other factors must contribute to the flux variability. Other research has shown that the $\mathrm{CO}_{2}$ efflux from snow-covered soils is sensitive to volumetric soil moisture and soil temperature (e.g. Oechel et al. 1997; Winston et al. 1997; Groffman et al. 2006; Monson et al. 2006). The lack of significant changes in these variables during DOY -11 to 19 (Fig. 6) suggests that $\mathrm{CO}_{2}$ emissions from the soil might be reasonably constant over this 30 day period; it is therefore also unlikely that the variability in the flux data is caused by changes in the $\mathrm{CO}_{2}$ source term. We, therefore, conducted further analysis of the 
potential role that advection may play in the measured $\mathrm{CO}_{2}$ concentrations and calculated diffusion fluxes in the snowpack.

Snowpack ventilation has been shown to be related directly to the high frequency pressure gradients that develop above the surface and inside the snowpack during windy conditions (Albert and Hawley 2002; Massman 2006; Massman and Frank 2006). From the differential pressure data, measured at 1-s resolution, the 10-min mean values (Fig. 7a), the standard deviation within each 10-min window (Fig. 7b), and the amplitude (Fig. 7c) were calculated for the corresponding time window. All three of these graphs show strong correlations between these variables, with the highest degree of correlation seen in the dependency of the standard deviation of the differential pressure data on the 10-min mean wind speed (Fig. 7b). Waddington et al. (1996) described that the forcing term, the pressure amplitude, has a 2nd order relationship with wind speed $\left(A_{\overline{\partial p}} \propto \bar{u}^{2}\right.$, where $A_{\overline{\partial p}}$ is the amplitude of the mean differential pressure and $\bar{u}$ is the mean wind speed). However, depending on the topography of the surrounding terrain, a 1st order relationship between pressure amplitude and wind speed $\left(A_{\bar{\partial} p} \propto \bar{u}\right)$ may be more appropriate (Massman and Frank 2006). Our regression analyses, examining different regression fits, resulted in a best fit (highest $r^{2}$ ) for the 1 st order relationship between differential pressure amplitude and 10-min mean wind speed (Fig. 7c). These analyses showed that the pressure amplitude was directly proportional to wind speed. Thus, it appeared appropriate to use wind speed as the forcing proxy for assessing advection.

In Figure 8a, concentration gradients from the $60-30 \mathrm{~cm}$ interval were plotted against the mean hourly wind speed during the measurement interval. With increasing wind speed, the magnitude of the $\mathrm{CO}_{2}$ concentration gradient $\left|\partial C_{\mathrm{CO}_{2}} / \partial z\right|$ became progressively smaller. The concentration gradient reached $-141 \mathrm{ppm} \mathrm{m}^{-1}$ at the highest recorded winds, while the gradient for zero wind conditions, as extrapolated from the 2nd order polynomial regression fit, was $-1,090 \mathrm{ppm} \mathrm{m}^{-1}$. Concentration gradients varied by a factor of $\sim 8$ under the wind conditions encountered during this experiment. As the concentration gradient translated proportionally to the final $\mathrm{CO}_{2}$ flux, the flux results shown in Fig. $8 \mathrm{~b}$ display a similar range of dependency, with calculated flux values at the highest
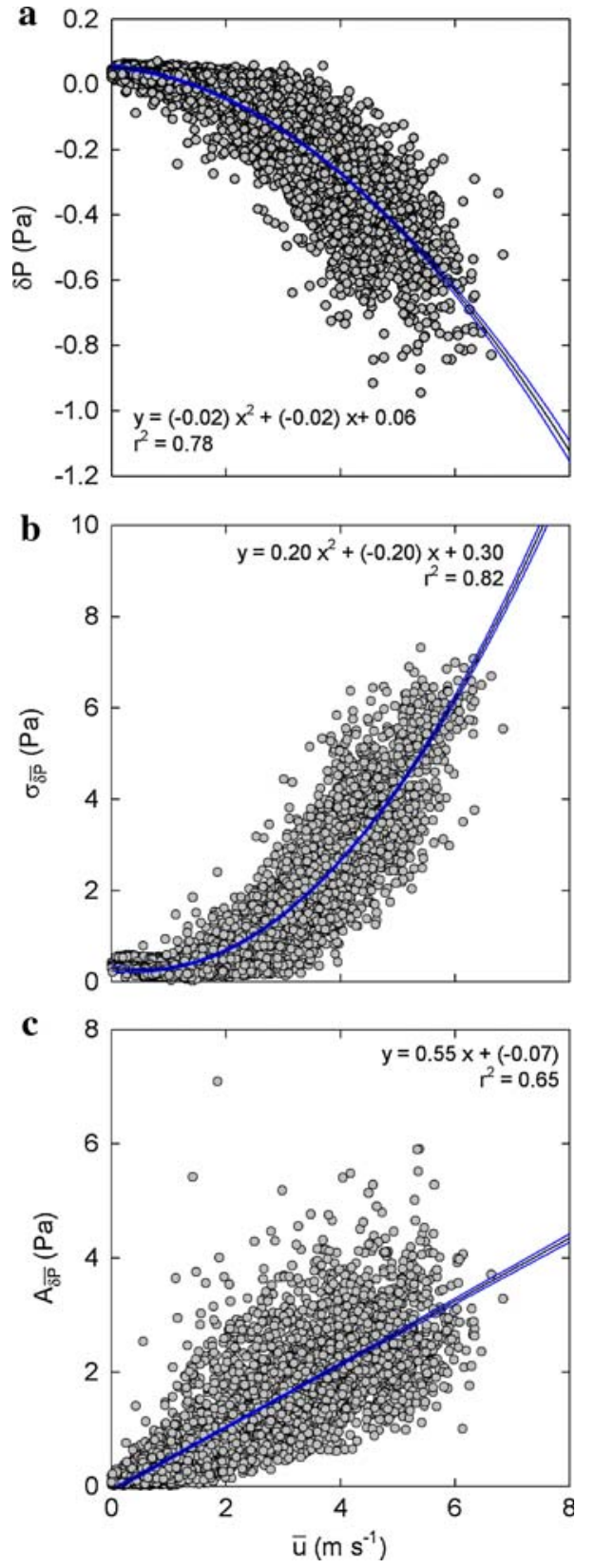

Fig. 7 Relationship between measures of the pressure fluctuations, representing the effect of wind pumping, as a function of absolute 10-min average wind. The differential pressure data represent $\mathbf{a}$ the mean of 1-s data, $\mathbf{b}$ the standard deviation of the 4,464 measurements within each 10-min interval, and c the mean value of the amplitudes that were calculated from the recorded maximum and minimum values during each minute. Regression curves shown are the selected best fit results of 1st and 2 nd order regression calculations that were examined. The blue curves represent the $95 \%$ confidence interval of the regression result (Color figure online) 


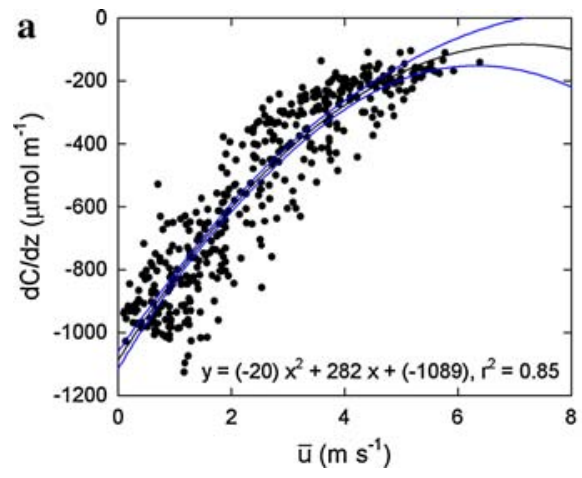

Fig. 8 a $\mathrm{CO}_{2}$ concentration gradient $\left(\partial \mathrm{C}_{\mathrm{CO}_{2}} / \partial z\right)$ and $\mathbf{b} \mathrm{CO}_{2}$ flux derived from inlets at 30 and $60 \mathrm{~cm}$ and wind speed from DOY -11 to 19 with 2 nd order polynomial fit solutions $\left(y=c x^{2}+b x+a\right)$. The blue curves depict the $95 \%$

winds dropping to a mere $1 / 8$ th of values derived under calm conditions.

Some of our earlier analyses of the diurnal dependency of the $\mathrm{CO}_{2}$ flux had suggested on average $25 \%$ flux increase between early morning and mid afternoon hours. Figure 9 illustrates this analysis by showing the mean hourly deviation from the daily mean flux values (for winters 2006 and 2007) that led to this assumption. The added wind speed data shed new light on this discussion. There was an obvious anti-correlation in the diurnal behavior of winds and calculated flux values, with higher winds coinciding with lower flux values and vice versa. Using the amplitudes of winter 2007 data series, the $0.3 \mathrm{~m} \mathrm{~s}^{-1}$ change in wind speed

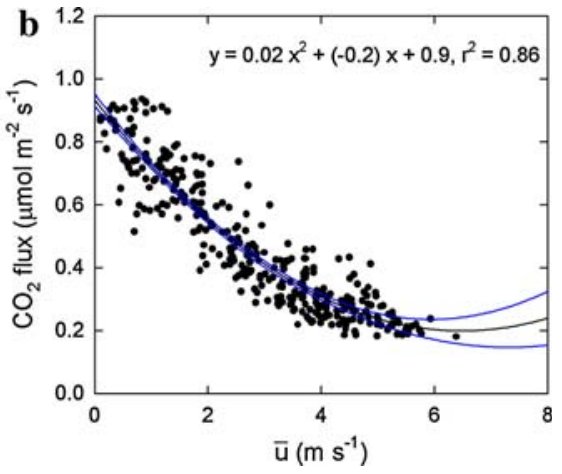

confidence interval for the fits. The $y$-intercept, $a$ term, would represent the $\mathrm{CO}_{2}$ concentration gradient and $\mathrm{CO}_{2}$ flux under zero wind condition (Color figure online)

corresponded to a $-0.05 \mu \mathrm{mol} \mathrm{m} \mathrm{m}^{-2} \mathrm{~s}^{-1}$ change in the diffusion-calculated $\mathrm{CO}_{2}$ flux. Similarly, for winter 2006, a $0.3 \mathrm{~m} \mathrm{~s}^{-1}$ change in wind speed yielded a $0.03 \mu \mathrm{mol} \mathrm{m} \mathrm{m}^{-2} \mathrm{~s}^{-1}$ change in $\mathrm{CO}_{2}$ flux. The winter 2007 result agreed with Fig. 10b, where similarly the slope of the regression function within the linear range predicted a $-0.06 \mu \mathrm{mol} \mathrm{m} \mathrm{m}^{-2} \mathrm{~s}^{-1}$ change in the diffusion- $\mathrm{CO}_{2}$ flux for a $0.3 \mathrm{~m} \mathrm{~s}^{-1}$ wind speed increase. Since results presented in Figs. $8 \mathrm{~b}$ and 9 were in qualitative agreement, results from the 30 day period of analysis shown in Fig. $8 \mathrm{~b}$ are expected to be representative for the entire season shown in Fig. 9.

Bowling et al. (2009) illustrated that the transport of trace gases through the snowpack at the C-1
Fig. 9 Deviation from daily means of wind speed (left $y$-axis) and $\mathrm{CO}_{2}$ flux (right $y$-axis) for winter 2006 and 2007. The error bars are the standard errors for each bin of data. The $\mathrm{CO}_{2}$ fluxes were calculated from the $60-30 \mathrm{~cm}$ concentration gradient for both winter 2006 and 2007

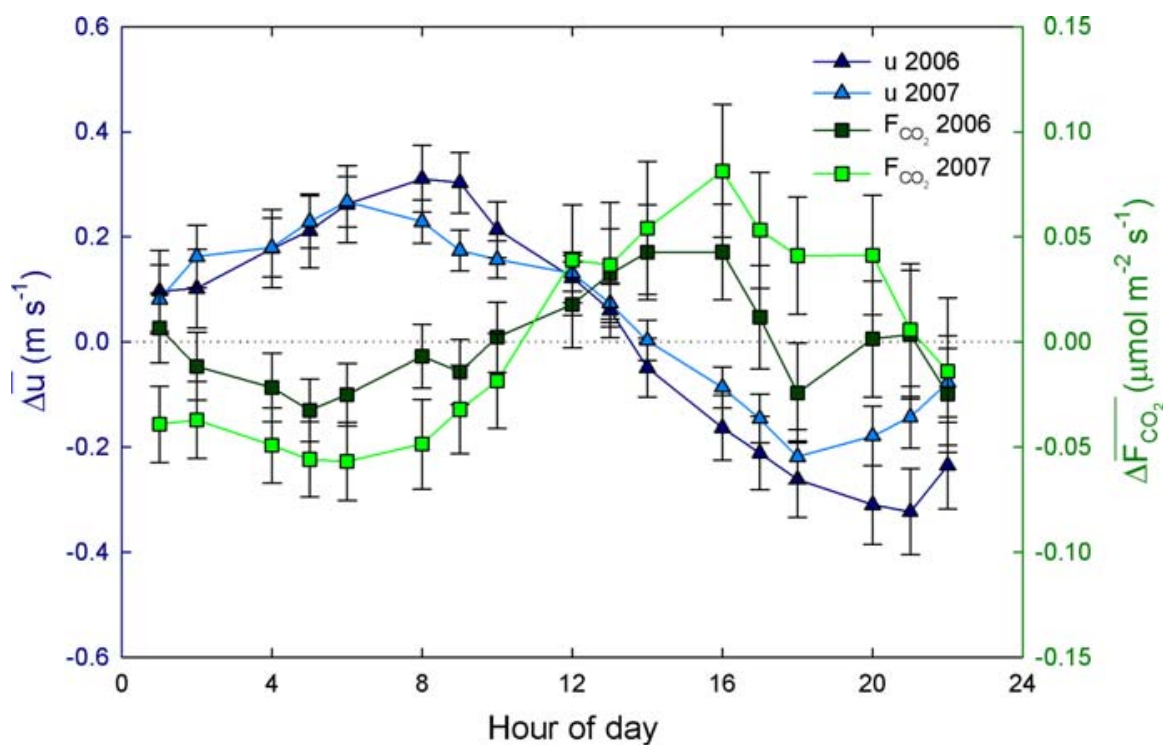


Ameriflux site on Niwot Ridge was dominated by diffusion with short-term variability driven by advection. Furthermore, they showed that the influence of diffusion was differentially apparent at greater depths. We evaluated how advection may change the concentrations of $\mathrm{CO}_{2}$ between the soil surface and the top of the snowpack by testing the relationship between $\mathrm{CO}_{2}$ concentrations at each inlet height and wind speed with 2nd order polynomial solutions $\left(y=c x^{2}+b x\right.$ $+a$ ) [Fig. 10]. The regression term $a$, denoting the zero-wind speed snowpack $\mathrm{CO}_{2}$ concentration at each inlet height, linearly increased going from the snow surface towards the bottom of the snowpack. The term $b$ demonstrates the "strength" of the wind's influence on the $\mathrm{CO}_{2}$ concentration. This value steadily increased towards the soil surface (going deeper into the snow), indicating that the wind effect on absolute $\mathrm{CO}_{2}$ levels was highest at the bottom of the snowpack, where absolute $\mathrm{CO}_{2}$ concentrations were the highest. Solutions for $c$ characterized the curvature of the best fit equation. Here, values increased towards the bottom of the snowpack, indicating an increasingly higher sensitivity towards winds deeper in the snow. $r^{2}$ values, denoting the quality of the regression fit, increased with increasing depth, showing again that the wind pumping effect was best described by these algorithms at the bottom of the snowpack. Lastly, the 95\% confidence interval demonstrated how at higher wind speeds, the uncertainty of $\mathrm{CO}_{2}$ concentration in the snowpack increases. An important conclusion from these analyses is that measurements made during high wind conditions would have increased errors in calculating $\mathrm{CO}_{2}$ gradients and for flux calculations. Similar to Bowling et al. (2009), our findings showed that advection effects at the bottom of the snowpack were described best by these algorithms.

To demonstrate the bias from wind pumping on flux results, $\mathrm{CO}_{2}$ fluxes calculated from concentration data, as obtained during actual wind speed conditions encountered during DOY -11 to 19 , were compared with fluxes derived from extrapolated gradients for zero wind speed conditions. These latter values were derived from the regression equations (intercept values of the regression solutions presented in Fig. 10). Fluxes were calculated in both ways for every sampling interval combination. While results for individual gradients showed a fair degree of variability, overall the findings shown in Fig. 11 illustrate that in every case higher flux values were
Fig. 10 Relationship between $\mathrm{CO}_{2}$ concentration measured at each inlet height above and in the snowpack and wind speed from DOY -11 to 19 with 2nd order polynomial fit $\left(y=c x^{2}+b x+a\right)$. The blue curve shows the $95 \%$ confidence interval for the 2 nd order fit. Coefficient values printed in red denote cases that are statistically significant $(p<0.05)$. The $y$-intercept, $a$ term, represents the extrapolated $\mathrm{CO}_{2}$ concentration under zero wind condition (Color figure online)

obtained for the wind-corrected calculation. The median flux value calculated from the in situ gradient data of $0.54 \mu \mathrm{mol} \mathrm{m} \mathrm{m}^{-2} \mathrm{~s}^{-1}$ accounts to $64 \%$ of the respective value derived from the wind-corrected calculation $\left(0.85 \mu \mathrm{mol} \mathrm{m} \mathrm{m}^{-2} \mathrm{~s}^{-1}\right)$. This finding defines the possible error that is associated with the application of Fick's law under neglect of wind pumping effects and the resulting underestimation of flux results.

\section{Summary and conclusions}

We have evaluated the DM method for studying wintertime $\mathrm{CO}_{2}$ fluxes at Niwot Ridge, Colorado. A particular advantage of this method stems from the reduced transfer rate (in comparison to ambient air) in the snowpack, resulting in largely elevated concentrations that build up inside the snow. This condition causes concentration gradients of gases released from the subniveal soil reach magnitudes that are much larger than above the surface, which allowed for their measurement with relatively simple analytical instruments. Deriving fluxes of these gases requires quantitative description of the gas transport in the airspace of the snowpack. Here, we used the by far most extensive dataset published to date to examine the commonly applied Fick's law of diffusion approach for computation of fluxes from these data.

Fluxes calculated from all possible gradients from eight inlet heights were found to generally agree within a factor of 1.5 with the overall median. Several factors contribute to variability and uncertainty in these data, with the error in the snow porosity and tortuosity variables, which both are indirectly derived from snow density measurements, being one of the major contributing factors. This research demonstrates how these uncertainties are reduced when data from several gradient heights can be statistically evaluated and combined for deriving a more representative, average flux value. 


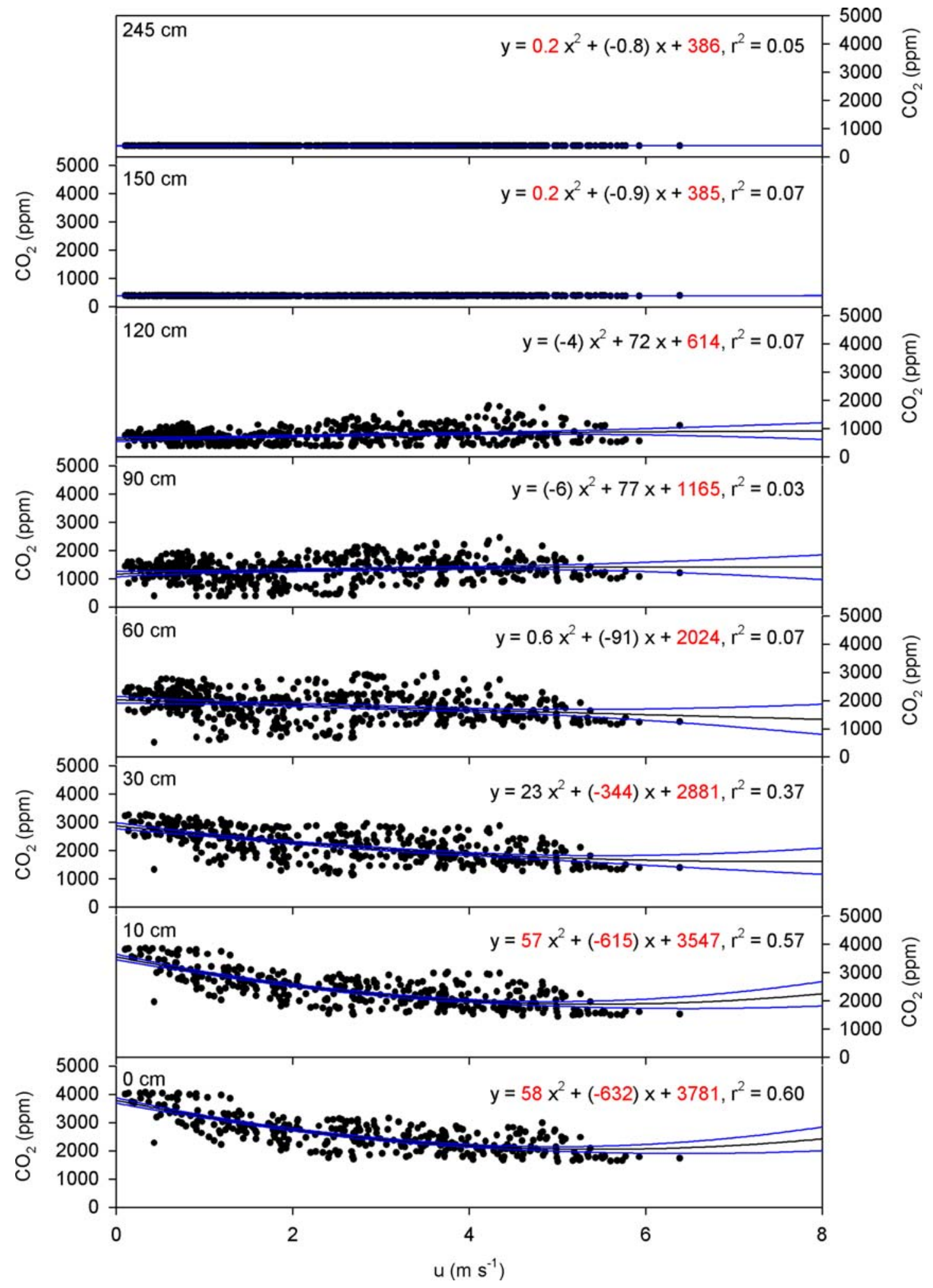


Fig. 11 Calculated flux under observed and inferred zero wind conditions for different concentration gradient intervals (category axis) from DOY -11 to 19 . The wind-corrected condition is derived from the $\left[\mathrm{CO}_{2}\right]$ versus wind speed relationship shown in Fig. 10. The medians for each scenario (observed and wind-corrected) are shown in its respective colored solid lines. For observed wind, the median flux is $0.54 \mu \mathrm{mol} \mathrm{m} \mathrm{m}^{-2} \mathrm{~s}^{-1}$. The median wind-corrected flux is $0.85 \mu \mathrm{mol} \mathrm{m} \mathrm{m}^{-2} \mathrm{~s}^{-1}$ (Color figure online)

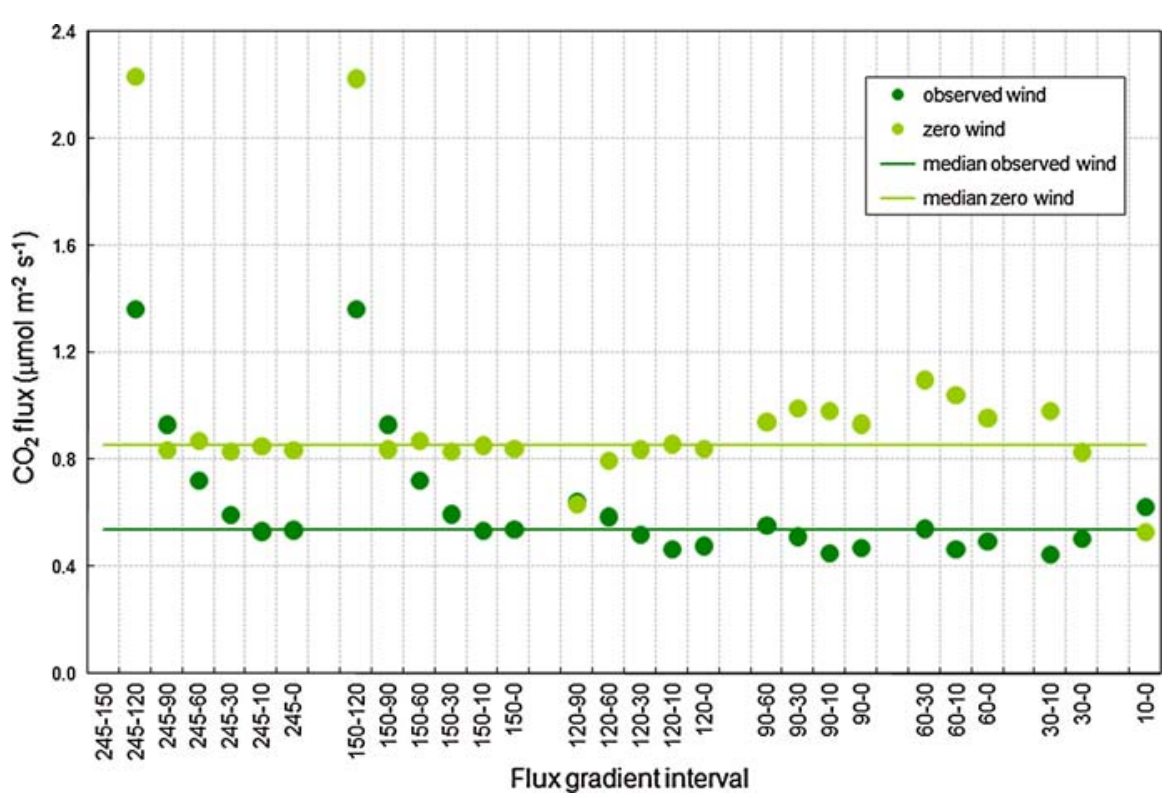

Using wind and differential pressure measurements, we were able to develop the constraints from the neglect of wind pumping on fluxes derived by the diffusion approach. Gas concentrations of soil emissions and their snowpack gradients in general declined with increasing winds, causing a negative bias on calculated fluxes, with fluxes calculated at the highest observed winds being less than $13 \%$ of those derived under no-wind conditions. Using an actual 3-week record from mid-winter, and averaging over all possible gradient combinations, it was determined that for conditions at this particular site fluxes calculated by the diffusion method, neglecting wind-pumping effects, were $36 \%$ lower than wind-corrected calculations.

Acknowledgments This research at Niwot Ridge, Colorado was funded by the Long-Term Ecological Research grant from the National Science Foundation (award\# NSF DEB9211776). This work was also supported by NSF grant OPP-0240976. B. Seok acknowledges the Biosphere-Atmosphere Research Training (BART) fellowship from the NSF-IGERT program administrated by the University of Michigan. We thank W. Massman, US Forest Service, Fort Collins, for fruitful discussions throughout this study, M. Losleben, University of Colorado at Boulder, for help with site maintenance and logistics, and many other University of Colorado colleagues for support and encouragement in the Niwot Ridge research projects. Any opinions, findings, and conclusions expressed in this material are those of the authors and do not necessarily reflect the views of the National Science Foundation.

Open Access This article is distributed under the terms of the Creative Commons Attribution Noncommercial License which permits any noncommercial use, distribution, and reproduction in any medium, provided the original author(s) and source are credited.

\section{References}

Albert MR, Hardy JP (1995) Ventilation experiments in a seasonal snow cover. In: Tonnessen KA, Williams MW, Tranter M (eds) Biogeochemistry of seasonally snowcovered catchments. IAHS Press, Wallingford, pp 41-49

Albert MR, Hawley RL (2002) Seasonal changes in snow surface roughness characteristics at Summit, Greenland: implications for snow and firn ventilation. Ann Glaciol 35:510-514. doi:10.3189/172756402781816591

Albert MR, Shultz EF (2002) Snow and firn properties and airsnow transport processes at Summit, Greenland. Atmos Environ 36:2789-2797. doi:10.1016/S1352-2310(02)001 19-X

Albert MR, Grannas AM, Bottenheim J, Shepson PB, Perron FE (2002) Processes and properties of snow-air transfer in the high Arctic with application to interstitial ozone at Alert, Canada. Atmos Environ 36:2779-2787. doi: 10.1016/S1352-2310(02)00118-8

Albert M, Shuman C, Courville Z, Bauer R, Fahnestock M, Scambos T (2004) Extreme firn metamorphism: impact of decades of vapor transport on near-surface firn at a lowaccumulation glazed site on the East Antarctic plateau. Ann Glaciol 39:73-78. doi:10.3189/172756404781814041

Bowling DR, Massman WJ, Schaeffer SM, Burns SP, Monson RK, Williams MW (2009) Biological and physical influences on the carbon isotope content of $\mathrm{CO} 2$ in a subalpine forest snowpack, Niwot Ridge, Colorado

Brooks PD, Williams MW (1999) Snowpack controls on nitrogen cycling and export in seasonally snow-covered catchments. Hydrol Process 13:2177-2190. doi:10.1002/(SICI) 1099-1085(199910)13:14/15<2177::AID-HYP850>3.0. $\mathrm{CO} ; 2-\mathrm{V}$ 
Brooks PD, Williams MW, Schmidt SK (1996) Microbial activity under alpine snowpacks, Niwot Ridge, Colorado. Biogeochemistry 32:93-113. doi:10.1007/BF00000354

Domine F, Albert M, Huthwelker T, Jacobi HW, Kokhanovsky AA, Lehning M, Picard G, Simpson WR (2008) Snow physics as relevant to snow photochemistry. Atmos Chem Phys 8:171-208

Duplessis JP, Masliyah JH (1991) Flow through isotropic granular porous-media. Transp Porous Media 6:207-221

Eisenberg D, Kauzmann W (1969) The structure and properties of water. Oxford University Press, Oxford

Erickson TA (2004) Development and application of geostatistical methods to modeling spatial variation in snowpack properties, Front Range, Colorado. University of Colorado at Boulder, Boulder, p 190

Fahnestock JT, Jones MH, Brooks PD, Walker DA, Welker JM (1998) Winter and early spring CO2 efflux from tundra communities of northern Alaska. J Geophys Res D 103:29023-29027

Filippa G, Freppaz M, Williams MW, Helmig D, Liptzin D, Seok B, Hall B, Chowanski K (2009) Winter and summer nitrous oxide and nitrogen oxides fluxes from a seasonally snow-covered subalpine meadow at Niwot Ridge, Colorado. Biogeochemistry. doi:10.1007/s10533-009-9304-1

Groffman PM, Hardy JP, Driscoll CT, Fahey TJ (2006) Snow depth, soil freezing, and fluxes of carbon dioxide, nitrous oxide and methane in a northern hardwood forest. Glob Chang Biol 12:1748-1760. doi:10.1111/j.1365-2486.2006. 01194.x

Hardy JP, Davis RE, Winston GC (1995) Evolution of factors affecting gas transmissivity of snow in the boreal forest. In: Tonnessen KA, Williams MW, Tranter M (eds) Biogeochemistry of seasonally snow-covered catchments. IAHS Press, Wallingford, pp 51-59

Helmig D, Seok B, Williams MW, Hueber J, Sanford JRL (2009) Fluxes and chemistry of nitrogen oxides in the Niwot Ridge, Colorado snowpack. Biogeochemistry. doi: 10.1007/s10533-009-9312-1

Hubbard RM, Ryan MG, Elder K, Rhoades CC (2005) Seasonal patterns in soil surface $\mathrm{CO} 2$ flux under snow cover in 50 and 300 year old subalpine forests. Biogeochemistry 73:93-107. doi:10.1007/s10533-004-1990-0

Jones HG, Pomeroy JW, Davies TD, Tranter M, Marsh P (1999) $\mathrm{CO} 2$ in Arctic snow cover: landscape form, in-pack gas concentration gradients, and the implications for the estimation of gaseous fluxes. Hydrol Process 13:2977-2989. doi:10.1002/(SICI)1099-1085(19991230)13:18<2977:: AID-HYP12>3.0.CO;2-\#

Liptzin D, Helmig D, Williams MW, Seok B, Filippa G, Chowanski K, Huber J (2009) Process level control on $\mathrm{CO}_{2}$ fluxes from a seasonally snow-covered subalpine meadow soil, Niwot Ridge, Colorado. Biogeochemistry. doi:10.1007/s10533-009-9303-2

Manly BFJ (1997) Randomization, bootstrap and Monte Carlo methods in biology. Chapman \& Hall, London

Mariko S, Nishimura N, Mo WH, Matsui Y, Kibe T, Koizumi $\mathrm{H}$ (2000) Winter CO2 flux from soil and snow surfaces in a cool-temperate deciduous forest, Japan. Ecol Res 15:363-372. doi:10.1046/j.1440-1703.2000.00357.x

Massman WJ (1998) A review of the molecular diffusivities of $\mathrm{H} 2 \mathrm{O}, \mathrm{CO} 2, \mathrm{CH} 4, \mathrm{CO}, \mathrm{O}-3, \mathrm{SO} 2, \mathrm{NH} 3, \mathrm{~N} 2 \mathrm{O}, \mathrm{NO}$, and
$\mathrm{NO} 2$ in air, O-2 and N-2 near STP. Atmos Environ 32:1111-1127. doi:10.1016/S1352-2310(97)00391-9

Massman WJ (2006) Advective transport of CO2 in permeable media induced by atmospheric pressure fluctuations: 1 . An analytical model. J Geophys Res-Biogeosci 111:14

Massman WJ, Frank JM (2006) Advective transport of CO2 in permeable media induced by atmospheric pressure fluctuations: 2. Observational evidence under snowpacks. J Geophys Res-Biogeosci 111:11

Massman WJ, Sommerfeld RA, Mosier AR, Zeller KF, Hehn TJ, Rochelle SG (1997) A model investigation of turbulence-driven pressure-pumping effects on the rate of diffusion of $\mathrm{CO}_{2}, \mathrm{~N}_{2} \mathrm{O}$, and $\mathrm{CH}_{4}$ through layered snowpacks. J Geophys Res D 102:18851-18863

Mast MA, Wickland KP, Striegl RT, Clow DW (1998) Winter fluxes of $\mathrm{CO}_{2}$ and $\mathrm{CH}_{4}$ from subalpine soils in Rocky Mountain National Park, Colorado. Global Biogeochem Cycles 12:607-620. doi:10.1029/98GB02313

McDowell NG, Marshall JD, Hooker TD, Musselman R (2000) Estimating $\mathrm{CO}_{2}$ flux from snowpacks at three sites in the Rocky Mountains. Tree Physiol 20:745-753

Monson RK, Sparks JP, Rosenstiel TN, Scott-Denton LE, Huxman TE, Harley PC, Turnipseed AA, Burns SP, Backlund B, Hu J (2005) Climatic influences on net ecosystem $\mathrm{CO}_{2}$ exchange during the transition from wintertime carbon source to springtime carbon sink in a high-elevation, subalpine forest. Oecologia 146:130-147. doi:10.1007/s00442-005-0169-2

Monson RK, Burns SP, Williams MW, Delany AC, Weintraub M, Lipson DA (2006) The contribution of beneath-snow soil respiration to total ecosystem respiration in a highelevation, subalpine forest. Global Biogeochem Cycles 20:13. doi:10.1029/2005GB002684

Musselman RC, Massman WJ, Frank JM, Korfmacher JL (2005) The temporal dynamics of carbon dioxide under snow in a high elevation rocky mountain subalpine forest and meadow. Arct Antarct Alp Res 37:527-538. doi: 10.1657/1523-0430(2005)037[0527:TTDOCD]2.0.CO;2

Oechel WC, Vourlitis G, Hastings SJ (1997) Cold season CO2 emission from arctic soils. Global Biogeochem Cycles 11:163-172. doi:10.1029/96GB03035

Roehm CL, Roulet NT (2003) Seasonal contribution of CO2 fluxes in the annual $\mathrm{C}$ budget of a northern bog. Global Biogeochem Cycles 17:9. doi:10.1029/2002GB001889

Seastedt TR (2001) Soils. In: Bowman WD, Seastedt TR (eds) Structure and function of an Alpine ecosystem: Niwot Ridge, Colorado. Oxford University Press, New York, pp 157-173

Seinfeld JH, Pandis SN (2006) Atmospheric chemistry and physics, 2nd edn. Wiley, Hoboken

Sommerfeld RA, Mosier AR, Musselman RC (1993) CO2, $\mathrm{CH} 4$ and $\mathrm{N} 2 \mathrm{O}$ flux through a wyoming snowpack and implications for global budgets. Nature 361:140-142. doi: 10.1038/361140a0

Sommerfeld RA, Massman WJ, Musselman RC, Mosier AR (1996) Diffusional flux of CO2 through snow: spatial and temporal variability among alpine-subalpine sites. Global Biogeochem Cycles 10:473-482. doi:10.1029/96GB01610

Soil Survey Staff (2006) Keys to soil taxonomy, 10th edn. USDA-Natural Resources Conservation Service, Washington 
Suzuki S, Ishizuka S, Kitamura K, Yamanoi K, Nakai Y (2006) Continuous estimation of winter carbon dioxide efflux from the snow surface in a deciduous broadleaf forest. J Geophys Res D 111:9

Takagi K, Nomura M, Ashiya D, Takahashi H, Sasa K, Fujinuma Y, Shibata H, Akibayashi Y, Koike T (2005) Dynamic carbon dioxide exchange through snowpack by wind-driven mass transfer in a conifer-broadleaf mixed forest in northernmost Japan. Global Biogeochem Cycles 19:10. doi:10.1029/2004GB002272

VanBochove E, Jones HG, Pelletier F, Prevost D (1996) Emission of $\mathrm{N} 2 \mathrm{O}$ from agricultural soil under snow cover: a significant part of $\mathrm{N}$ budget. Hydrol Process 10:15451549. doi:10.1002/(SICI)1099-1085(199611)10:11<15 45::AID-HYP492>3.0.CO;2-0

Waddington ED, Cunningham J, Harder S (1996) The effects of snow ventilation on chemical concentrations. In: Wolff EW, Bales RC (eds) Chemical exchange between the atmosphere and polar snow. Springer, Berlin, pp 403-452

Welker JM, Fahnestock JT, Jones MH (2000) Annual CO2 flux in dry and moist arctic tundra: field responses to increases in summer temperatures and winter snow depth. Clim Change 44:139-150. doi:10.1023/A:1005555012742

Williams MW, Helmig D, Blanken P (2009) Introduction: white on green: under-snow microbial processes and trace gas fluxes through snow, Niwot Ridge, Colorado Front Range. Biogeochemistry (this issue)

Williams MW, Brooks PD, Mosier A, Tonnessen KA (1996) Mineral nitrogen transformations in and under seasonal snow in a high-elevation catchment in the Rocky Mountains, United States. Water Resour Res 32:3161-3171. doi:10.1029/96WR02240

Williams MW, Brooks PD, Seastedt T (1998) Nitrogen and carbon soil dynamics in response to climate change in a high-elevation ecosystem in the Rocky Mountains, USA. Arct Alp Res 30:26-30. doi:10.2307/1551742

Williams MW, Sommerfeld R, Massman S, Rikkers M (1999) Correlation lengths of meltwater flow through ripe snowpacks, Colorado Front Range, USA. Hydrol Process 13:1807-1826. doi:10.1002/(SICI)1099-1085(199909)13: 12/13<1807::AID-HYP891>3.0.CO;2-U

Williams MW, Seibold C, Chowanski K (2009) Storage and release of solutes from a seasonal snowpack : soil and stream water response, Niwot Ridge, Colorado. Biogeochemistry. doi:10.1007/s10533-009-9288-X

Winston GC, Sundquist ET, Stephens BB, Trumbore SE (1997) Winter CO2 fluxes in a boreal forest. J Geophys Res D 102:28795-28804

Yashiro Y, Mariko S, Koizumi H (2006) Emission of nitrous oxide through a snowpack in ten types of temperate ecosystems in Japan. Ecol Res 21:776-781. doi: 10.1007/s11284-006-0174-x

Zimov SA, Davidov SP, Voropaev YV, Prosiannikov SF, Semiletov IP, Chapin MC, Chapin FS (1996) Siberian $\mathrm{CO} 2$ efflux in winter as a $\mathrm{CO} 2$ source and cause of seasonality in atmospheric CO2. Clim Change 33:111-120. doi:10.1007/BF00140516 